\title{
Diagnostic Accuracy of Ultrasound and Doppler Study for Post-Surgical Surveillance in Patients with Breast Cancer
}

\author{
SAHAR ELFIKY, M.D.; SAMAR R. RAGHEB, M.D. and ISRAA H. AL-JUMAILI, M.Sc. \\ The Department of Diagnostic Radiology, Faculty of Medicine, Ain Shams University
}

\begin{abstract}
Background: Breast cancer (BC) is one of the most common cancers among the women population all over the world. It is also the one of the leading causes of death among that population. Advances in early diagnosis and $\mathrm{BC}$ treatment, a combination of surgery, chemotherapy, and radiation therapy, in the past decades have resulted in prolonged survival in patients with BC. However, the major problem for the BC management is still its local-regional recurrence and distant metastasis in $\mathrm{BC}$ patients who have previously undergone surgery.
\end{abstract}

Aim of Study: To evaluate the diagnostic accuracy of postoperative surveillance by ultrasound and Doppler study in breast cancer patients correlated to pathology as golden reference.

Patients and Methods: In this diagnostic accuracy study of 20 female patients with breast cancer subjected to surgical management within one year whether mastectomy or conservative surgery, breast U/S done to the patient with colour Doppler study to characterised the lesion. Radiology department of Tikrit University Hospital under supervision of Diagnostic Radiology, Ain Shams University. Diagnostic Radiology, Ain Shams University. Study period: From May 2020 till January 2021.

Results: Based on histopathology (biopsy), as the reference standard, we analyzed the capacity of US and Doppler study scan to identify the lesions. US (FAST) yielded two false negative results in the identification of traumatic injuries. The sensitivity of US was $88.24 \%$ and its specificity $100 \%$; the positive and negative predictive values were $100 \%$ and $60 \%$, respectively with accuracy $90 \%$. These results show that US had high sensitivity and specificity in the detection of breast lesion and differentiate between benign \& malignant lesions. US surveillance results according to final diagnosis, there were 17 US-positive findings in 15 malignant patients. In our study, there was no significant difference in the overall survival between patients with benign lesions only and patients with malignant lesions.

Conclusion: The results of this study demonstrated that Post surveillance Ultrasound (PSU) can be used for detection of the malignant lesions in the breast regional area with $\mathrm{BC}$. Postoperative US had a high sensitivity for the detection of

Correspondence to: Dr. Israa H. Al-Jumaili, E-Mail: israljumaily@gmail.com malignant lesions in the breast and associated breast region, which can be a predictor of distant metastasis in mastectomy and breast conservation surgery patients.

Key Words: Breast cancer.

\section{Introduction}

BREAST cancer (BC) is one of the most common cancers among the women population all over the world [1]. Breast cancers can begin in different areas of the breast, such as the ducts, the lobules, or the tissue in between [2].

$\mathrm{BC}$ is predominantly a disease of aging, with only 5 to $7 \%$ of patients diagnosed below the age of 40 years in the developed world. In less developed regions such as in Africa and the Middle East, a higher proportion of patients are diagnosed below the age of 40 , reaching as high as $20 \%$ [3]

Increasing age, reproductive factors, mammographic density and, in around $9 \%$ of cases, genetic factors and family history are all known risk factors for breast cancer [4].

Based on criteria of pathological features and invasiveness, common breast cancers can be divided into three major groups: Non-invasive (or in situ), invasive, and metastatic breast cancers [2] .

Postoperative imaging demonstrates abnormalities associated with skin-incision sites, repositioning of the nipple areola complex (NAC), and parenchymal redistribution [5].

Postoperative U/S has a high sensitivity for the detection of malignant lesions in the breast and associated breast region, which can be a predictor of distant metastasis in mastectomy patient's Doppler sonography is preferred when suspicious lesions are discovered within the context of underlying postoperative changes. U/S and Doppler 
study can also provide a more accurate characterization of suspected lesions than physical examinations, and it allows for immediate intervention for the tissue diagnosis of such suspicious lesions [6]. In contrast to mammography, the detection performance of U/S is not affected by dense breast tissue. The main limitation of U/S is the high number of non-specific or false-positive findings, although this is less of a problem if U/S is performed on a regular basis during follow-up [7]

\section{Aim of the work:}

The aim of this study is to evaluate the diagnostic accuracy of postoperative surveillance by ultrasound and Doppler study in breast cancer patients correlated to pathology as golden reference.

\section{Patients and Methods}

\section{Methodology:}

Type of study: In this diagnostic accuracy study of 20 female patients with breast cancer subjected to surgical management within one year whether mastectomy $14(70 \%)$ or conservative surgery 6 (30\%), breast U/S done to the patient with colour Doppler study to characterised the lesion.

Study setting: Radiology department of Tikrit university hospital under supervision of Director: Prof. Dr. Sahar Elfiky Diagnostic Radiology, Ain Shams University and Co-Director: Dr. Samar Ramzy Ragheb. Diagnostic Radiology, Ain Shams University.

\section{Study period: From May 2020 Jan. 2021.}

Study population: 20 female patients whether mastectomy or conservative surgery.

Inclusion criteria: Patients $>18$ years old with breast cancer within first year after surgery. Pathologically proven breast cancer, subjected to surgical management whether mastectomy or conservative surgery.

Exclusion criteria: Breast cancer patient who did not receive surgical management. Patients they lost to ultrasound follow-up less than 3 years. Patients less than 18 years. Patients with synchronous or past history of other malignancy.

Sample method: Using Convenience method.

Sample size: 20 cases.

Ethical considerations: Detailed explanation of the procedure to the patient including the steps, outcomes and complications obtaining informed consent from the patient.
Study tools and procedure: Machine used is hospital type Alpenion cube High density linear transducer (12MHz). Breast ultrasound and Doppler sonography not required any special preparations it was also important to avoid applying powders, lotions, or other cosmetic to patient breast before the procedure. Full history will be taken from all patients. Ask the patient to uncover area from waist up and to lie on ultrasound table. Put triangular sponge behind the shoulder that help us to examined breast effective. Applying clear ultrasonic gel to the skin and examine surgical scar bed, ipsilateral axilla and supraclavicular fossa ultrasound guided fine needle or core biopsy if the suspicious lesion in surgical scar in selected patients adjunct to mammography or MRI after data collection.

Risk of procedure: Minor bleeding, hematoma formation or patient discomfort after biopsy.

Statistical analysis: Appropriate descriptive and inferential statistical test will be used.

Table (1): Demographic characteristics of studied patients.

\begin{tabular}{|c|c|c|}
\hline \multirow[t]{2}{*}{ Parameters } & \multicolumn{2}{|c|}{$\begin{array}{l}\text { Study group } \\
\quad(\mathrm{n}=20)\end{array}$} \\
\hline & $\mathrm{N}$ & $\%$ \\
\hline $\begin{array}{l}\text { Age (years): } \\
\text { Mean } \pm \mathrm{SD} \\
\text { Median (IQR) } \\
\text { Range }\end{array}$ & & \\
\hline $\begin{array}{l}\text { Age distribution: } \\
30-<40 \text { years } \\
40-<50 \text { years } \\
50-<60 \text { years } \\
\geq 60 \text { years }\end{array}$ & $\begin{array}{l}2 \\
7 \\
8 \\
3\end{array}$ & $\begin{array}{l}10.0 \\
35.0 \\
40.0 \\
15.0\end{array}$ \\
\hline $\begin{array}{l}\text { Occupation: } \\
\text { House Wife }\end{array}$ & 20 & 100.0 \\
\hline $\begin{array}{l}\text { Residence: } \\
\text { Rural } \\
\text { Urban }\end{array}$ & $\begin{array}{l}10 \\
10\end{array}$ & $\begin{array}{l}50.0 \\
50.0\end{array}$ \\
\hline
\end{tabular}

Table (1) shows the demographic characteristics of studied patients. The age of studied females was ranged from 33 to 70 years with mean \pm SD was $49.5 \pm 9.316$ years and median of 50 years. The commonest age involved was $(50-<60$ years) group with $8(40.0 \%)$ cases followed by $(40-<50$ years $)$ group with 7 (35.0\%) cases. The age group least involved was (30-<40 years) with $2(10 \%)$ cases. All the studied patients were housewives, half $(50 \%)$ of them were from urban areas and the other half were living in rural areas. 


\section{Statistical consideration:}

Data will be collected, tabulated and subjected to adequate statistical analysis including mean and standard deviation and will be discussed to assess the accuracy of ultrasound post-surgical surveillance in patients with breast cancer.

\section{Results}

Table (2) illustrates the basic clinical characteristics of studied patients. Two (10\%) patients were diabetic, two (10\%) patients were hypertensive and only one patient was found to have hyperlipidemia.

Table (3) shows the clinical characteristics related to breast cancer in studied patients. 11 $(55.0 \%)$ cases had lesions in the left side. The mean tumor size was $(4.27 \pm 1.4) \mathrm{cm} .8(40 \%)$ cases underwent lumpectomy, 14 (70\%) cases were treated by modified radical mastectomy, $11(55 \%)$ cases were on chemotherapy, 9 (45\%) cases were still on hormonal therapy and $8(40 \%)$ cases were on radiotherapy. Vascularity were observed in $9(45 \%)$ cases.

The tumors pathologically were classified into 5 benign and 15 malignant tumors. Benign tumors included 1 reactive hyperplasic lymphoid cell with no malignant cells, 1 seroma, 1 scar granuloma and 1 ductal epithelial cells of apocrine type. Malignant tumors included 9 ductal carcinoma, 2 mammary carcinoma and 1 tubular carcinoma.

Table (5) shows Ultrasound findings in studied patients. The majority of cases $(70 \%)$ showed irregular hypoechoic focal lesion on US. 3 (15\%) showed mass lesion.

Based on histopathology (biopsy), as the reference standard, we analyzed the capacity of US scan to identify the lesions. US (FAST) yielded two false negative results in the identification of traumatic injuries.

The sensitivity of US was $88.24 \%$ and its specificity $100 \%$; the positive and negative predictive values were $100 \%$ and $60 \%$, respectively with accuracy $90 \%$. These results show that US had high sensitivity and specificity in the detection of breast lesion and differentiate between benign \& malignant lesions $(p=0.009)$.

Table (7) illustrates US surveillance results according to final diagnosis, there were 17 USpositive findings in 15 malignant patients.

In our study, there was no significant difference in the overall survival between patients with benign lesions only and patients with malignant lesions $(p=0.293)$.

Table (2): Basic clinical characteristics of studied patients.

\begin{tabular}{lll}
\hline & \multicolumn{2}{c}{$\begin{array}{c}\text { Study group } \\
(\mathrm{n}=20)\end{array}$} \\
\cline { 2 - 3 } Parameters & $\mathrm{N}$ & $\%$ \\
\hline Diabetes mellitus: & & \\
No & 18 & 90.0 \\
Yes & 2 & 10.0 \\
Hypertension: & & \\
No & 18 & 90.0 \\
Yes & 2 & 10.0 \\
Hyperlipidemia: & & \\
No & 19 & 95.0 \\
Yes & 1 & 5.0 \\
\hline
\end{tabular}

N: Number. \%: Percentage.

Table (3): Clinical characteristics related to breast cancer in studied patients.

\begin{tabular}{|c|c|c|}
\hline \multirow[t]{2}{*}{ Parameters } & \multicolumn{2}{|c|}{$\begin{array}{l}\text { Study group } \\
\quad(\mathrm{n}=20)\end{array}$} \\
\hline & $\mathrm{N}$ & $\%$ \\
\hline \multicolumn{3}{|l|}{ Side: } \\
\hline Right & 9 & 45.0 \\
\hline Left & 11 & 55.0 \\
\hline \multicolumn{3}{|l|}{ Size: } \\
\hline Mean \pm SD & \multicolumn{2}{|c|}{$4.27 \pm 1.4$} \\
\hline Median (IQR) & \multicolumn{2}{|c|}{$4.26(3.21-5.16)$} \\
\hline Range & \multicolumn{2}{|c|}{$2.36-7.23$} \\
\hline \multicolumn{3}{|l|}{ Lumpectomy: } \\
\hline No & 12 & 60.0 \\
\hline Yes & 8 & 40.0 \\
\hline \multicolumn{3}{|c|}{$\begin{array}{l}\text { Modified Radical Mastectomy } \\
(\text { MRM): }\end{array}$} \\
\hline No & 6 & 30.0 \\
\hline Yes & 14 & 70.0 \\
\hline \multicolumn{3}{|c|}{ Chemotherapy (CTH): } \\
\hline No & 9 & 45.0 \\
\hline Yes & 11 & 55.0 \\
\hline \multicolumn{3}{|c|}{ Still on hormonal therapy: } \\
\hline No & 11 & 55.0 \\
\hline Yes & 9 & 45.0 \\
\hline \multicolumn{3}{|l|}{ Radiotherapy: } \\
\hline No & 12 & 60.0 \\
\hline Yes & 8 & 40.0 \\
\hline \multicolumn{3}{|l|}{ Vascularity: } \\
\hline No & 11 & 55.0 \\
\hline Yes & 9 & 45.0 \\
\hline
\end{tabular}

SD : Standard deviation. $\quad \mathrm{N}$ : Number. IQR: Interquartile range. $\quad \%$ : Percentage. 
Table (4): Histopathology characteristics in studied patients. Table (5): Ultrasound findings in studied patients.

\begin{tabular}{|c|c|c|c|c|c|}
\hline \multirow{3}{*}{ Parameters } & \multirow{2}{*}{\multicolumn{2}{|c|}{$\begin{array}{c}\text { Study group } \\
(\mathrm{n}=20)\end{array}$}} & \multirow{2}{*}{ Parameters } & \multicolumn{2}{|c|}{ Study group $(n=20)$} \\
\hline & & & & $\mathrm{N}$ & $\%$ \\
\hline & $\mathrm{N}$ & $\%$ & \multirow{7}{*}{$\begin{array}{l}\text { Ultrasound: } \\
\text { Irregular hypoechoic focal lesion } \\
\text { Mass lesion } \\
\text { Cystic lesion of fluid collection } \\
\text { Well defined localized cystic lesion } \\
\text { heterogeneous } \\
\text { Spots of macro calcifications }\end{array}$} & & \\
\hline Benign cases $(n=5)$ : & \multirow{4}{*}{1} & \multirow{4}{*}{5.0} & & 14 & 70.0 \\
\hline Reactive hyperplasic lymphoid cell & & & & 3 & 15.0 \\
\hline with no malignant cells & & & & 1 & 5.0 \\
\hline & & & & 1 & 5.0 \\
\hline Seroma & 1 & 5.0 & & & \\
\hline Scar granuloma & 1 & 5.0 & & 1 & 5.0 \\
\hline BIRDIS II & 1 & 5.0 & \multirow{3}{*}{\multicolumn{3}{|c|}{$\begin{array}{l}\text { N: Number. } \% \text { : Percentage. } \\
\text { Table (6): Validity of US for post-surgical surveillance in } \\
\text { patients with breast cancer. }\end{array}$}} \\
\hline Ductal epithelial cells of apocrine type & 1 & 5.0 & & & \\
\hline \multicolumn{3}{|l|}{ Malignant cases $(n=15)$ : } & & & \\
\hline Poorly differentiated breast carcinoma & 1 & 5.0 & \multirow{2}{*}{$\begin{array}{ll}\text { Sensi- } & \text { Speci- } \\
\text { tivity } & \text { ficity }\end{array}$} & \multirow{2}{*}{$\begin{array}{c}\text { Acc- } \\
\text { uracy AUC }\end{array}$} & \multirow{2}{*}{$\begin{array}{c}p- \\
\text { value }\end{array}$} \\
\hline Ductal carcinoma & 9 & 45.0 & & & \\
\hline Suspicion for malignancy & 2 & 10.0 & \multirow{2}{*}{$\begin{array}{l}\text { US } \\
\text { findings }\end{array}$} & \multirow{2}{*}{\multicolumn{2}{|c|}{$90 \% 0.9410 .009$}} \\
\hline Mammary carcinoma & 2 & 10.0 & & & \\
\hline Tubular carcinoma & 1 & 5.0 & \multirow{2}{*}{$\begin{array}{l}\text { *PPV: Positive Predictive Value. } \\
\text { NPV: Negative Predictive Value. } \\
\text { AUC: Area under curve. }\end{array}$} & & \\
\hline $\begin{array}{l}\text { N: Number. } \\
\% \text { : Percentage. }\end{array}$ & & & & & \\
\hline
\end{tabular}

Table (7): US surveillance results according to vascularity and the final diagnosis.

\begin{tabular}{|c|c|c|c|c|c|c|}
\hline $\begin{array}{l}\text { Patient } \\
\text { no. }\end{array}$ & Ultrasound & Type of surgery & Size & $\begin{array}{l}\text { Vascu- } \\
\text { larity }\end{array}$ & Biopsy & $\begin{array}{l}\text { Type of } \\
\text { lesion }\end{array}$ \\
\hline 1 & $\begin{array}{l}\text { Irregular hypoechoic } \\
\text { focal lesion }\end{array}$ & Modified Radical Mastectomy & 2.38 & Yes & $\begin{array}{l}\text { Poorly differentiated } \\
\text { breast carcinoma }\end{array}$ & Malignant \\
\hline 2 & $\begin{array}{l}\text { Irregular hypoechoic } \\
\text { focal lesion }\end{array}$ & Modified Radical Mastectomy & 3.2 & No & Ductal carcinoma & Malignant \\
\hline 3 & $\begin{array}{l}\text { Irregular hypoechoic } \\
\text { focal lesion }\end{array}$ & Modified Radical Mastectomy & 4.52 & No & Suspicion for malignancy & Malignant \\
\hline 4 & $\begin{array}{l}\text { Irregular hypoechoic } \\
\text { focal lesion }\end{array}$ & Lumpectomy & 3.8 & No & Mammary carcinoma & Malignant \\
\hline 5 & Mass lesion & Modified Radical Mastectomy & 4.2 & Yes & Ductal carcinoma & Malignant \\
\hline 6 & $\begin{array}{l}\text { Irregular hypoechoic } \\
\text { focal lesion }\end{array}$ & Lumpectomy & 4.6 & No & Intraductal carcinoma & Malignant \\
\hline 7 & $\begin{array}{l}\text { Irregular hypoechoic } \\
\text { focal lesion }\end{array}$ & Modified Radical Mastectomy & 5 & Yes & $\begin{array}{l}\text { Reactive hyperplasic } \\
\text { lymphoid cell with no } \\
\text { malignant cells }\end{array}$ & Benign \\
\hline 8 & $\begin{array}{l}\text { Cystic lesion of fluid } \\
\text { collection }\end{array}$ & Modified Radical Mastectomy & 5.21 & No & Seroma & Benign \\
\hline 9 & $\begin{array}{l}\text { Irregular hypoechoic } \\
\text { focal lesion }\end{array}$ & Modified Radical Mastectomy & 6.12 & No & Tubular carcinoma & Malignant \\
\hline 10 & $\begin{array}{l}\text { Well defined localized } \\
\text { cystic lesion heterogeneous }\end{array}$ & Modified Radical Mastectomy & 3.48 & Yes & Scar granuloma & Benign \\
\hline 11 & Spots of macro calcifications & Modified Radical Mastectomy & 6.4 & No & BIRDIS II & Benign \\
\hline 12 & $\begin{array}{l}\text { Irregular hypoechoic } \\
\text { focal lesion }\end{array}$ & Lumpectomy & 2.95 & Yes & Intraductal carcinoma & Malignant \\
\hline 13 & $\begin{array}{l}\text { Irregular hypoechoic } \\
\text { focal lesion }\end{array}$ & Lumpectomy & 2.364 & Yes & $\begin{array}{l}\text { Ductal epithelieal cells } \\
\text { of apocrine type }\end{array}$ & Benign \\
\hline 14 & $\begin{array}{l}\text { Irregular hypoechoic } \\
\text { focal lesion }\end{array}$ & Modified Radical Mastectomy & 4.33 & No & Mammary carcinoma & Malignant \\
\hline 15 & $\begin{array}{l}\text { Irregular hypoechoic } \\
\text { focal lesion }\end{array}$ & Modified Radical Mastectomy & 6.1 & No & Ductal carcinoma & Malignant \\
\hline 16 & $\begin{array}{l}\text { Irregular hypoechoic } \\
\text { focal lesion }\end{array}$ & $\begin{array}{l}\text { Modified Radical Mastectomy } \\
\text { and lumpectomy }\end{array}$ & 7.23 & Yes & Suspicion for malignancy & Malignant \\
\hline 17 & Mass lesion & Modified Radical Mastectomy & 2.41 & No & Intraductal carcinoma & Malignant \\
\hline 18 & $\begin{array}{l}\text { Irregular hypoechoic } \\
\text { focal lesion }\end{array}$ & $\begin{array}{l}\text { Lumpectomy \& Modified } \\
\text { Radical Mastectomy }\end{array}$ & 3.57 & Yes & Intraductal carcinoma & Malignant \\
\hline 19 & $\begin{array}{l}\text { Irregular hypoechoic } \\
\text { focal lesion }\end{array}$ & Lumpectomy & 3.25 & No & Ductal carcinoma & Malignant \\
\hline 20 & Mass lesion & $\begin{array}{l}\text { Lumpectomy \& Modified } \\
\text { Radical Mastectomy }\end{array}$ & 4.32 & Yes & Intraductal carcinoma & Malignant \\
\hline
\end{tabular}


Table (8): Survival rate between breast cancer lesion.

\begin{tabular}{cccc}
\hline & \multicolumn{3}{c}{ Overall comparisons } \\
\cline { 2 - 4 } & Chi-square & $p$-value & Sig. \\
\hline Log rank (Mentel-Cox) & 1.106 & 0.293 & NS \\
- Test of equality of survival distributions for the different levels of type of lesions. \\
\hline
\end{tabular}

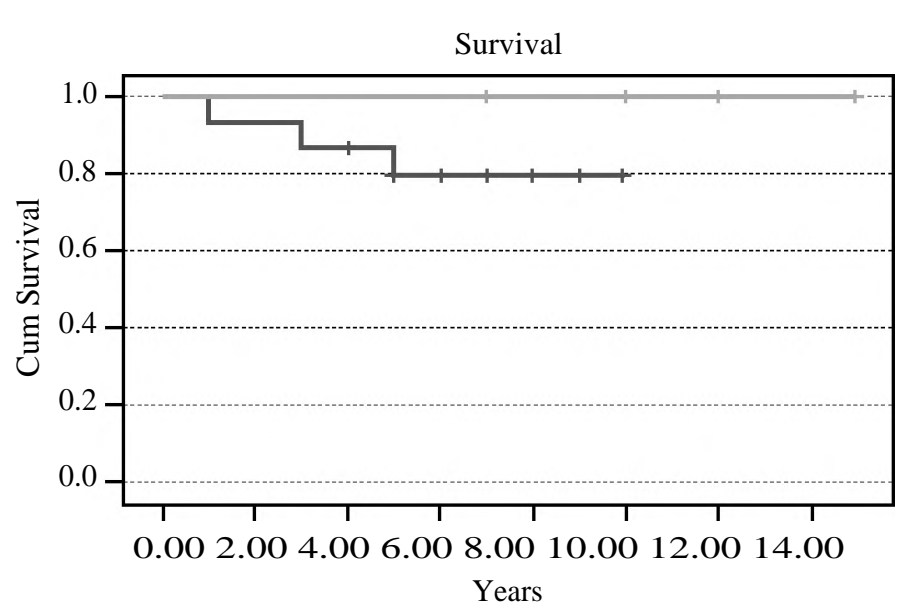

Fig. (1): Kaplan-Meier survival curves for patients with benign and malignant breast lesions.
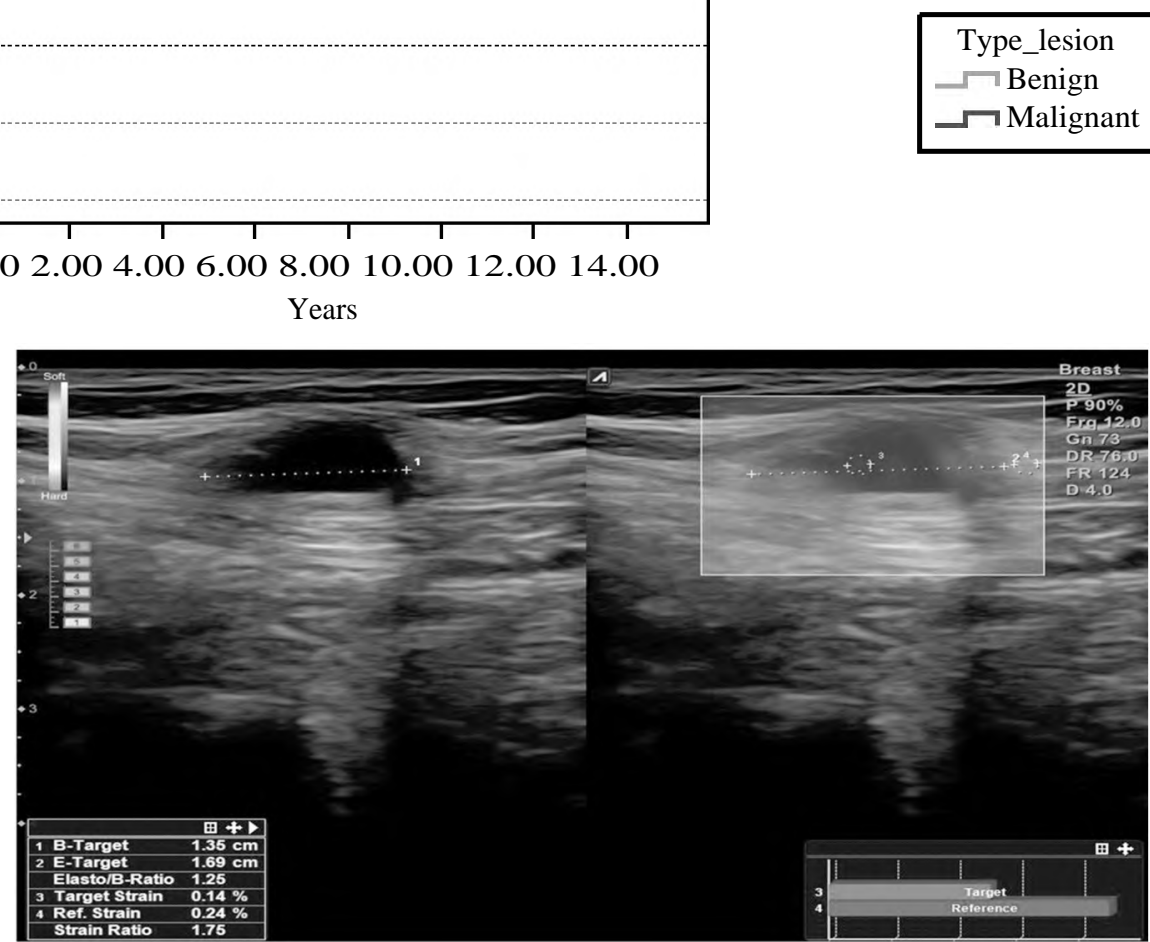

Fig. (2): A 55-years-old female with a history of breast cancer underwent modified radical mastectomy (MRM) \& chemotherapy (CTH).

Regular follow-up ultrasound scan along the operative bed discovered an irregular, hypoechoic focal lesion along the scar measured $1.4 \times 1.7 \mathrm{~cm}$. Doppler study confirms intra lesion positive vascularity.

FNA biopsy was done and the recurrence of breast cancer was confirmed pathologically as a poorly differentiated breast carcinoma.

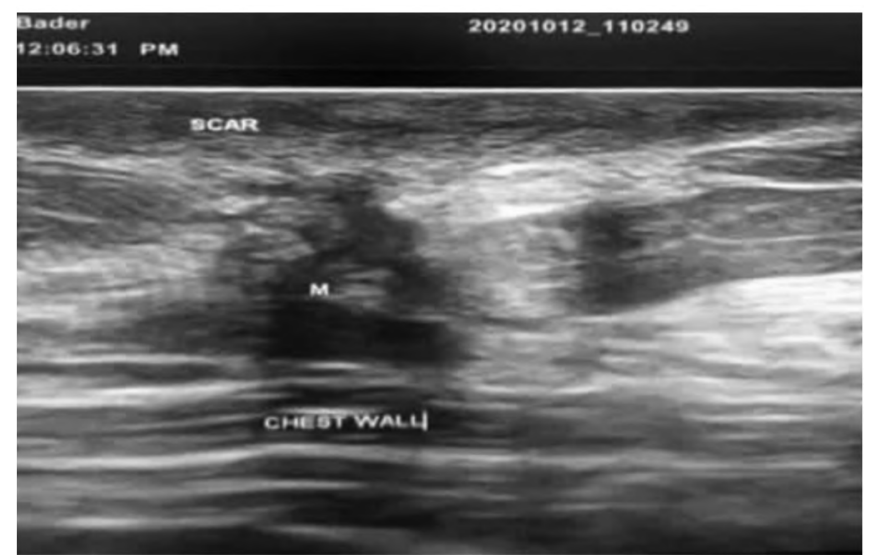

Fig. (3): A 50-year-old female with a history of LT breast cancer underwent MRM \& CTH.

Follow-up US along the operative scar discovered an irregular hypo echoic lesion. No vascularity could be identified by Doppler.

FNA biopsy was done $\&$ recurrence of breast cancer was confirmed as a recurrent ductal carcinoma. 


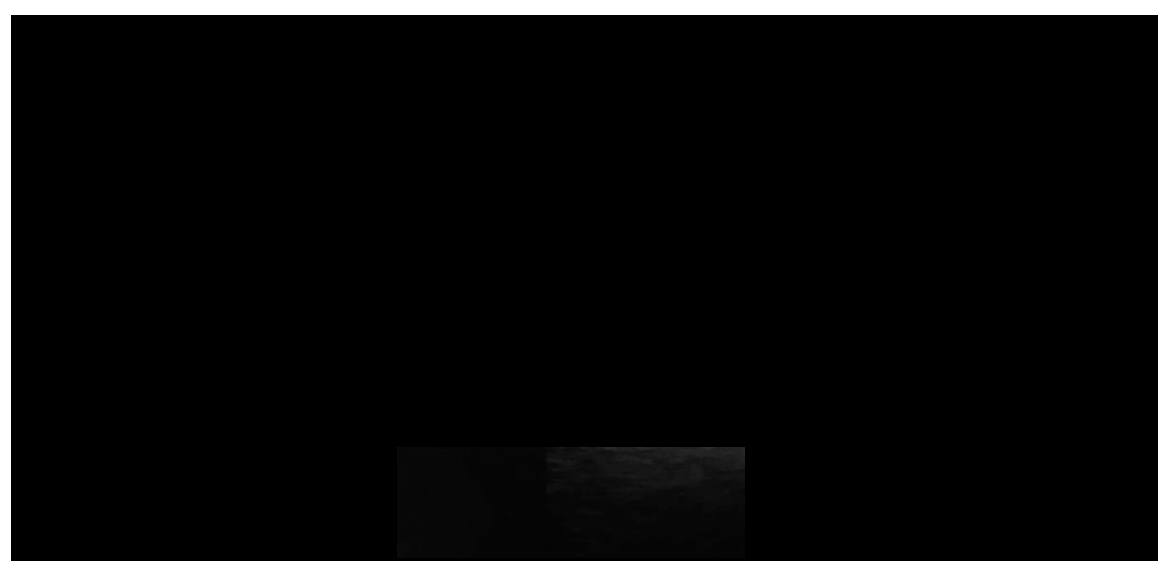

Fig. (4): A 45 yrs old female, with previous history of Lt breast cancer underwent mastectomy before 2 year.

Us finding hypo echoic focal lesion irregular in shape in surgical bed, non-vascular by Doppler study.

Core tissue biopsy was done: Show cluster and few scatter hyperplasic epithelial cell with moderate atypia and stoma element in bloody background, C4 (suspicion for malignancy).

\section{Discussion}

Breast cancer (BC) is one of the most common cancers among the women population all over the world. It is also the one of the leading causes of death among that population. Advances in early diagnosis and BC treatment, a combination of surgery, chemotherapy, and radiation therapy, in the past decades have resulted in prolonged survival in patients with BC.

However, the major problem for the $\mathrm{BC}$ management is still its local-regional recurrence and distant metastasis in BC patients who have previously undergone surgery. It has been reported that early detection of its recurrence can not only help to control the disease and its treatment, but also can help to improve the survival for BC patients after surgery [8]

Breast cancer is the leading cause of cancerrelated death among women worldwide, with variable incidence and mortality rates. Fortunately, mortality has decreased because of advances in screening and treatment. The 10-year survival rate of breast cancer ranges from 70 to $80 \%$, with up to $90 \%$ for local and $60 \%$ for regional disease [7]

The annual hazard of recurrent disease (local and or metastases) ranges between 2 and $5 \%$ in years 5-20 after diagnosis. The yield for recurrent disease is likely to be higher in patients with advanced stages of disease [9].

Recent studies have demonstrated that the onset of local recurrence is an independent predictor for survival. Thus management of patients with breast cancer during surveillance plays an important role.
The aims of any follow-up are to detect early local recurrence or contralateral breast cancer and to diagnose and treat cancer and/or therapy-related diseases such as metastases and osteoporosis [10]

Considering these facts a well-defined, evidence-based surveillance protocol is needed to manage patients with breast cancer after the initial diagnosis, including staging and follow-up. Currently mammography every $1-2$ years is the only recommended evidence-based imaging modality. In asymptomatic patients, there are no data to indicate that any imaging or laboratory test leads to a survival benefit. In symptomatic patients or in case of clinical findings appropriate tests should be performed immediately [11]

Breast ultrasound, which is used in highresource settings to supplement mammography in certain clinical scenarios, offers a potentially viable alternative for early breast cancer detection in some resource-limited areas because it is portable, lower cost than mammography, and versatile across a wider range of clinical applications. Breast ultrasound has been proven to be an exceptionally effective tool for imaging palpable abnormalities in the breast. It distinguishes cystic from solid masses and demonstrates those features of solid masses that would denote the mass as suspicious and warranting biopsy [12] .

Ultrasound is a particularly useful diagnostic modality in dense breast tissue, often detecting breast cancers obscured on mammography. Furthermore, if biopsy is required, ultrasound is the ideal imaging tool to guide subsequent procedures, further enhancing its utility in breast cancer diagnosis [13]. 
The main purpose of this study was to evaluate the diagnostic accuracy of postoperative surveillance by ultrasound and Doppler study in breast cancer patients correlated to pathology as golden reference.

This was a cross sectional diagnostic accuracy study to 20 female patients with breast cancer subjected to surgical management within one year whether mastectomy or conservative surgery, breast U/S done to the patient with colour Doppler study to characterised the lesion.

As regard the demographic characteristics of studied patients, we found that the age of studied females was ranged from 33 to 70 years with mean $\pm \mathrm{SD}$ was $49.5 \pm 9.316$ years and median of 50 years. The commonest age involved was $(50-<60$ years) group with $8(40.0 \%)$ cases followed by $(40-<50$ years) group with $7(35.0 \%)$ cases. The age group least involved was (30-<40 years) with $2(10 \%)$ cases. All the studied patients were housewives, half $(50 \%)$ of them were from urban areas and the other half were living in rural areas.

In agreement with our study, the study of Liu et al., [1] aimed to evaluate the clinical usefulness of postoperative surveillance by ultrasound (PSU) in patients after breast cancer surgery, and reported that the mean age of all included patients was $(45.9 \pm 11.2)$ years. All patients were Chinese and Han ethnicity.

Another retrospective study of Suh et al., [6] aimed to assess the diagnostic performance of postoperative ultrasound (US) surveillance for the detection of malignant lesions, and reported that the mean age of all included patients was 47.5 (2073) years.

Many breast cancer survivors have coexistent chronic diseases or comorbidities at the time of their cancer diagnosis. Women with breast cancer have similar risks as those without cancer for developing chronic illnesses or comorbidities due to the natural effects of aging; however cancer survivors are at risk for chronic conditions (such as obesity, hypertension, diabetes, dyslipidemia and decreased bone mass) not only because of the natural aging process, but sometimes due to the late effects of cancer treatment [14].

In the current study, as regard the basic clinical characteristics of studied patients; two (10\%) patients were diabetic, two (10\%) patients were hypertensive and only one patient was found to have hyperlipidemia.
Sharma et al., [15] reported that the most prevalent comorbidities associated with breast cancer are hypertension (21.8\%), chronic obstructive pulmonary disease (COPD) (19.9\%), rheumatologic disease $(18.6 \%)$, and diabetes mellitus (16.7\%), all four conditions have been reported in around $75 \%$ of the cases.

Fu et al., [16] reported that among the 134 breast cancer patients, $73.8 \%$ had at least one of the comorbidities, $54.7 \%$ had $2-4$, and only $7.4 \%$ had $5-8$. The five most prevalent comorbidities in this patient population were as follows: Hypertension $(32.8 \%)$, arthritis $(32.8 \%)$, thyroid problem $(22.4 \%)$ hypercholesterolemia (12.7\%) and diabetes $(12.0 \%)$.

In the present study, as regard the clinical characteristics related to breast cancer in studied patients, $11(55.0 \%)$ cases had lesions in the left side. The mean tumor size was $(4.27 \pm 1.4) \mathrm{cm} .8$ (40\%) cases underwent lumpectomy, 14 (70\%) cases were treated by modified radical mastectomy, $11(55 \%)$ cases were on chemotherapy, 9 (45\%) cases were still on hormonal therapy and $8(40 \%)$ cases were on radiotherapy. Vascularity was observed in $9(45 \%)$ cases.

In comparison with the study of Liu et al., [1] which reported that the mean tumor size was

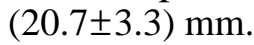

Another study of Suh et al., [6] reported that 286 mastectomy patients, 103 breast conservation surgery (BCS) patients, and one with both mastectomy and BCS, the mean tumor size was 21.3 (473) $\mathrm{mm}$.

Breast cancer is a heterogeneous disease, varying from clinical presentation to molecular features, and tends to exhibit potentially distinct prognosis. Among the integrity of histological subtypes for the cancer of the breast, ductal breast cancer (IDC) is the most common histological type, which occupy more than $75 \%$ proportion of the entire population [17].

Furthermore, in the current study; the tumors pathologically were classified into 5 benign and 15 malignant tumors. Benign tumors included 1 reactive hyperplasic lymphoid cell with no malignant cells, 1 seroma, 1 scar granuloma and 1 ductal epithelial cells of apocrine type. Malignant tumors included 9 ductal carcinoma, 2 mammary carcinoma and 1 tubular carcinoma.

While in the study of Liu et al., [1] histopathology included invasive ductal cancer $(n=269)$, in- 
vasive lobular cancer $(\mathrm{n}=11)$, ductal cancer in situ $(n=19)$, lobular cancer in situ $(n=5)$, mucinous cancer $(n=7)$, medullary cancer $(n=6)$, carbriform cancer $(n=4)$, and papillary cancer $(n=3)$.

Rambau et al., [18] reported that Majority of the patients had invasive ductal carcinoma $(91.5 \%)$ followed by mucinous carcinoma (5.2\%), Invasive lobular carcinoma (3\%) and in situ ductal carcinoma $(0.3 \%)$. In all patients, $185(56.4 \%)$ had tumor with histological grade 3 .

Moreover, the study of Suh et al., [6] reported that according to histopathological distribution; Invasive ductal carcinoma 331 (82.9), Ductal carcinoma-in-situ 32 (8.0), Mucinous carcinoma 8 (2.0), Lobular carcinoma 7 (1.7), Medullary carcinoma 6 (1.5), Papillary carcinoma 5 (1.3), Cribriform carcinoma 4 (1.0), Metaplastic carcinoma 2 (0.5), Apocrine carcinoma 2 (0.5), Tubular carcinoma 1 (0.3), and Malignant phyllodes 1 (0.3).

Although mammography is widely accepted as the gold standard for early breast cancer detection, it is not widely available globally. In contrast, ultrasound is accessible, versatile, and cost effective [19].

Breast US is an ideal complementary technique to the clinical exam and mammography. It enables direct correlation with and work-up of clinical as well as mammographic findings. In addition, US is able to evaluate the chest wall or the reconstructed breast after mastectomy. Breast ultrasound is also an excellent tool to evaluate the regional lymph nodes. In contrast to mammography, the detection performance of US is not affected by dense breast tissue [7].

On the other hand, Ultrasound findings in studied patients revealed that the majority of cases $(70 \%)$ showed irregular hypoechoic focal lesion on US. 3 (15\%) showed mass lesion.

In comparison with the study of Brom et al., [20] which reported that all imaging episodes, 199 abnormal images were generated. Of these abnormal images, $168(84.4 \%)$ were reported as 107 by US, Twenty-five images (12.6\%) were classified as category 4 lesions 18 by US and 7 by mammography and 6 images $(3.0 \%)$ were considered category 5,3 by US and 3 by mammography. One hundred and eight percutaneous biopsies were performed, 78 (72.2\%) of which were triggered by US alone. From 70 mammographic abnormal findings, $33(47.1 \%)$ lead to biopsy, in US, 129 abnormal images were found and $95(73.6 \%)$ of abnormal findings lead to biopsy.
Based on histopathology (biopsy), as the reference standard, we analyzed the capacity of US scan to identify the lesions. US (FAST) yielded two false negative results in the identification of traumatic injuries. The sensitivity of US was $88.24 \%$ and its specificity $100 \%$; the positive and negative predictive values were $100 \%$ and $60 \%$, respectively with accuracy $90 \%$. These results show that US had high sensitivity and specificity in the detection of breast lesion and differentiate between benign $\&$ malignant lesions ( $p=0.009)$.

Liu et al., [1] reported that the results of ultrasound surveillance for final-positive lesions (FPL) after surgery were assessed. The SS, SC, UAFPL, and PPV included mastectomy bed (SS, 100.0\%; SC, 99.7\%; UAFPL, 99.7\%; and PPV, 36.0\%), contralateral breast (SS, $100.0 \%$; SC, $99.0 \%$; UAFPL, 99.0\%; and PPV, 25.4\%), ipsilateral axillary or supraclavicular (SS, 91.7\%; SC, 99.4\%; UAFPL, 99.4\%; and PPV, 25.6\%), and contralateral axilla or supraclavicular lymph nodes (SS, $100.0 \%$; SC, 99.9\%; UAFPL, 99.9\%; and PPV, 33.3\%).

Suh et al., [6] reported that among 2,925 examinations in 287 patients with mastectomy, there were 85 US-positive and 23 final-positive lesions $(27 \%)$ in 20 patients at final diagnosis. Among 1,171 examinations in 104 BCS patients, there were 32 US positive and five final-positive (15.6\%) findings in four patients. The sensitivity, specificity, positive predictive value, and accuracy of US for final-positive lesions after breast cancer surgery were 95.8, 97.8, 27.1, and 97.9\% in mastectomy patients and 42.9, 97.5, 9.4, and 97.2\% in BCS patients. Among mastectomy patients, patients with final-positive findings had a higher incidence of distant metastasis than patients without finalpositive findings (31.6 vs. $9.3 \%, p=0.01$ ). Among BCS patients, there was no distant metastasis. Among mastectomy patients, the overall survival was not significantly different between patients with only final-positive findings and in patients with final-positive findings and distant metastasis.

As routine ancillary ultrasound surveillance remains debated, most publishing bodies do not recommend routine ultrasound surveillance, In the prospective multicenter ACRIN 6666 trial of Berg et al., [21], which included a subgroup of 1,426 female breast cancer survivors with heterogeneously dense breast tissue in at least one quadrant, women were randomized to a sequence of three yearly screenings with mammography alone or a combination of mammography and ultrasound, Subgroup analysis of women with a personal history of breast cancer was included in the supplementary online content. Addition of ultrasound significantly 
$(p<0.001)$ increased cancer detection from 8.2/ 1,000 to $12.5 / 1,000$ screens and sensitivity from 55.9 to $84.7 \%$. However, specificity and PPV3 were significantly $(p<0.001)$ inferior after the addition of ultrasound.

In a meta-analysis of Sood et al., [19], of the 526 identified studies, 26 were eligible for inclusion. Ultrasound had an overall pooled sensitivity and specificity of $80.1 \%$ (95\% CI, $72.2 \%$ to $86.3 \%$ ) and $88.4 \%$ (95\% CI, $79.8 \%$ to $93.6 \%$ ), respectively. When only low- and middle-income country data were considered, ultrasound maintained a diagnostic sensitivity of $89.2 \%$ and specificity of $99.1 \%$.

Tan et al., [22] in which a total of 326 breast lesions were biopsied. Histology results revealed the presence of 74 breast cancers and 252 benign lesions. USG had a sensitivity of $82 \%$, specificity of $84 \%$, PPV $=60 \%$, NPV $=94 \%$ and an accuracy of $84 \%$. MMG had a sensitivity of $49 \%$, specificity of $89 \%, \mathrm{PPV}=53 \%, \mathrm{NPV}=88 \%$ and an accuracy of $81 \%$. A total of 161 lesions which were imaged with both modalities were analyzed to determine the significance in the differences in sensitivity and specificity between USG and MMG. Sensitivity of USG $(75 \%)$ was significantly higher than sensitivity of MMG (44\%) $(\mathrm{X}(2) 1=6.905, p=0.014)$. Specificity of MMG (91\%) was significantly higher than specificity of USG (79\%) $(\mathrm{X}(2) 1=27.114$, $p<0.001)$. Compared with MMG, the sensitivity of USG was $50 \%$ (95\% CI 10\%-90\%) higher in women aged less than 50 years $(\mathrm{X}(2) 1=0.000$, $p=1.000)$ and $27 \%$ (95\% CI 19\%-36\%) higher in women aged 50 years and above $(\mathrm{X}(2) 1=5.866$, $p=0.015)$.

In the study on our hands, US surveillance results according to final diagnosis, there were 17 US-positive findings in 15 malignant patients.

Liu et al., [1] reported that Ninety-four ultrasound positive lesions in 71 patients were found in this study. Of those, 25 were malignant lesions, and 69 were benign lesions.

However, in a clinical setting, it is difficult to perform a postoperative US that is focused on a specific part of the abovementioned area. Thus, a further evaluation of postoperative US for the detection of malignant lesions in mastectomy sites, the remaining breast, and regional LNs is needed. The study populations in previous studies consist of heterogeneous patient groups because they included patients with postoperative breast US examinations within a certain study period. Therefore, patients had variable postoperative periods (range 7-300 months) [23].
In our study, there was no significant difference in the overall survival between patients with benign lesions only and patients with malignant lesions $(p=0.293)$.

In agreement with our findings, Suh et al., [6] reported that there was no significant difference in the overall survival between patients with finalpositive lesions only and patients with final-positive lesions and distant metastasis in the mastectomy group. Asymptomatic patients with final-positive findings had no significant difference in the overall survival compared with symptomatic patients with final-positive findings $(p<0.05)$.

The strength of our study is that we included patients with $\mathrm{BC}$ who received both the mastectomy and the breast conservation surgery, so we are sure that it still works in patients with $\mathrm{BC}$ who received breast conservation surgery.

\section{Conclusion:}

The results of this study demonstrated that PSU can be used for detection of the malignant lesions in the breast regional area with BC. Postoperative US had a high sensitivity for the detection of malignant lesions in the breast and associated breast region, which can be a predictor of distant metastasis in mastectomy and breast conservation surgery patients.

\section{References}

1- LIU Y.Q., DONG J.N., MENG Q.X., SUN P. and ZHANG J.: Ultrasound for postoperative surveillance after mastectomy in patients with breast cancer: A retrospective study', Medicine (Baltimore), 96 (52): e9244, 2017.

2- FENG Y., SPEZIA M., HUANG S., YUAN C., ZENG Z., ZHANG L., JI X., LIU W., HUANG B., LUO W., LIU B., LEI Y., DU S., VUPPALAPATI A., LUU H.H., HAYDON R.C., HE T.C. and REN G.: Breast cancer development and progression: Risk factors, cancer stem cells, signaling pathways, genomics, and molecular pathogenesis', Genes and Diseases, 5 (2): 77-106, 2018.

3- AZIM H.A. and PARTRIDGE A.H.: Biology of breast cancer in young women', Breast Cancer Research, 16 (4): 427,2014

4- THOMSON A.K., HEYWORTH J.S., GIRSCHIK J., SLEVIN T., SAUNDERS C. and FRITSCHI L.: Beliefs and perceptions about the causes of breast cancer: A casecontrol study', BMC Research Notes, 7: 558, 2014.

5- MARGOLIS N.E., MORLEY C., LOTFI P., SHAYLOR S.D., PALESTRANT S., MOY L. and MELSAETHER A.N.: Update on Imaging of the Postsurgical Breast', RadioGraphics, 34 (3): 642-660, 2014.

6- SUH Y.J., KIM M.J., KIM E.K., MOON H.J., KIM S.I. and PARK B.W.: Value of ultrasound for postoperative surveillance of asian patients with history of breast cancer surgery: A single-center study', Annals of Surgical Oncology, 20 (11): 3461-3468, 2013. 
7- BICK U. and HELBICH T.H.: Follow-Up of Patients with Breast Cancer: Imaging of Local Recurrence and Distant Metastases', Diseases of the Chest, Breast, Heart and Vessels, 167-178, 2019.

8- PACE M.M., SHARMA B., ANDERSON-DAM J., et al. Ultrasound-guided thoracic paravertebral blockade: A retrospective study of the incidence of complications. Anesth. Analg., 122: 1186-91, 2016.

9- SENKUS E., KYRIAKIDES S., PENAULT-LLORCA F., et al.: Primary breast cancer: ESMO Clinical Practice Guidelines for diagnosis, treatment and follow-up. Ann. Oncol., 24: vi7-vi23, 2013.

10- YOON J.H., KIM M.J., KIM E.K. and MOON H.J.: Imaging surveillance of patients with breast cancer after primary treatment: current recommendations. KJR, 16: 219-28, 2015

11- MOY L., BAILEY L., D'ORSI C., et al.: ACR appropriateness criteria stage I breast cancer: Initial workup and surveillance for local recurrence and distant metastases in asymptomatic women. J. Am. Coll. Radiol., 14: S28292, 2017.

12- BAE M.S., MOON W.K., CHANG J.M., et al.: Breast cancer detected with screening US: Reasons for nondetection at mammography. Radiology, 270: 369-377, 2014.

13- SHETTY M.K.: Screening and diagnosis of breast cancer in low-resource countries: What is state of the art? Semin Ultrasound CT MR, 32: 300-305, 2011.

14- EDGINGTON A. and MORGAN M.A.: Looking beyond recurrence: Comorbidities in cancer survivors. Clinical Journal of Oncology Nursing, 15 (1): 3-12, 2011.

15- SHARMA N., NARAYAN S., SHARMA R., KAPOOR A., KUMAR N. and NIRBAN R.: Association of comorbidities with breast cancer: An observational study. Trop. J. Med. Res., 19 (2): 168-71, 2016.
16- FU X., LEI Z., WANG K. and YAN J.: Low cost carrier competition and route entry in an emerging but regulated aviation market-the case of China. Transportation Research Part A: Policy and Practice, 79: 3-16, 2015.

17- YERUSHALMI R., HAYES M.M. and GELMON K.A. Breast carcinoma - rare types: Review of the literature. Ann. Oncol., 20: 1763-70, 2009.

18- RAMBAU P.F., CHALYA P.L., MANYAMA M.M. and JACKSON K.J.: Pathological features of Breast Cancer seen in Northwestern Tanzania: A nine years retrospective study. BMC research notes, 4 (1): 1-6, 2011.

19- SOOD R., ROSITCH A.F., SHAKOOR D., AMBINDER

E., POOL K.L., POLLACK E., MOLLURA D.J., MULLEN L.A. and HARVEY S.C.: Ultrasound for breast cancer detection globally: A systematic review and metaanalysis. Journal of Global Oncology, 5: 1-7, 2019.

20- BROMLEY L., XU J., LOH S.W., CHEW G., LAU E. and YEO B.: Breast ultrasound in breast cancer surveillance; incremental cancers found at what cost?. The Breast, 54: 272-7, 2020.

21- BERG W.A., ZHANG Z., LEHRER D., JONG R.A., PISANO E.D., BARR R.G., BÖHM-VÉLEZ M., MAHONEY M.C., EVANS W.P., LARSEN L.H. and MORTON M.J.: Detection of breast cancer with addition of annual screening ultrasound or a single screening MRI to mammography in women with elevated breast cancer risk. JAMA, 307 (13): 1394-404, 2012.

22- TAN K.P., RUMAISA M.P., MR S.A., RADHIKA S., NURISMAH M.I., NORLIA A. and ZULFIQAR M.A. The comparative accuracy of ultrasound and mammography in the detection of breast cancer. The Medical Journal of Malaysia, 69 (2):79-85, 2014.

23- MOON H.J., KIM M.J., KIM E.K., et al.: US surveillance of regional lymph node recurrence after breast cancer surgery. Radiology, 252: 673-81, 2009. 


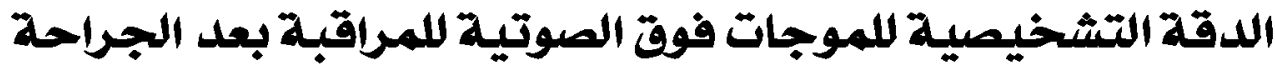

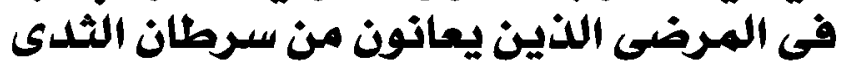

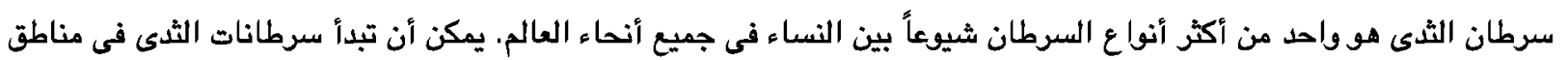

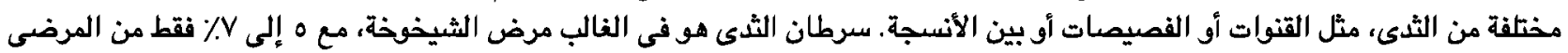

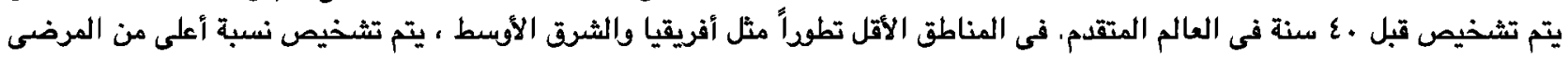

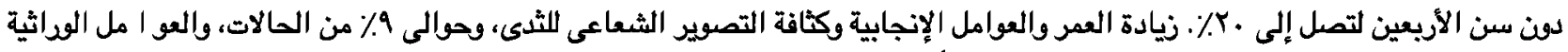

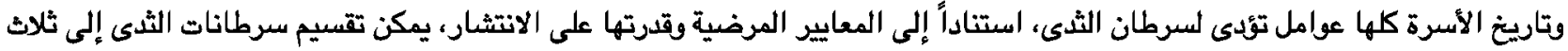

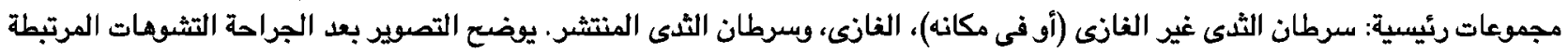

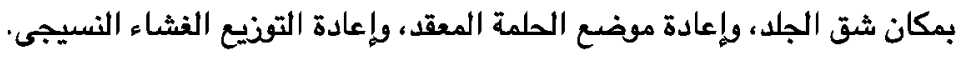

لدى الموجات فوق الصوتية بعد الجراحة حساسية عالية للكثف عن الآفات الخبيثة فى الثىى والمنطقة المرتبطة به، والتى يمكن أن تكون

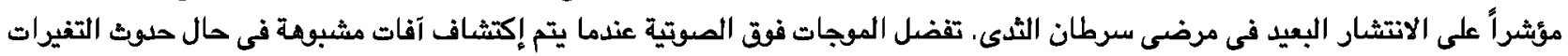

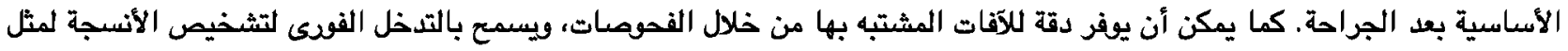

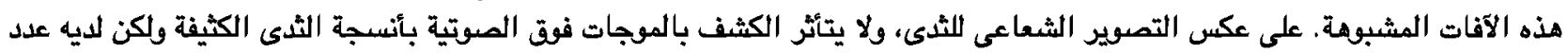

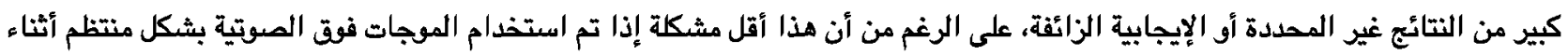
المتابعة.

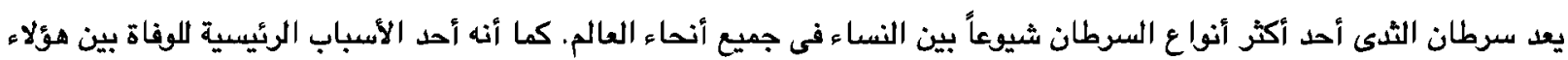

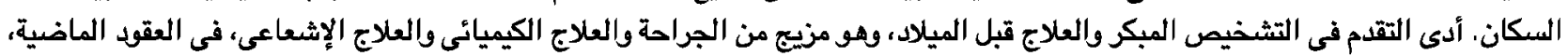

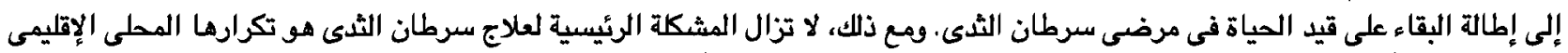

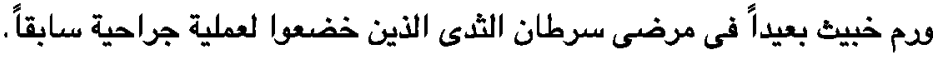

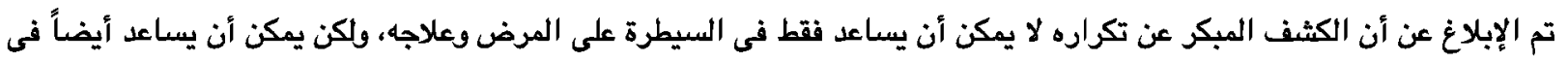

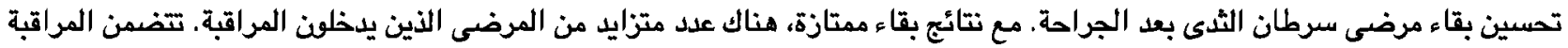

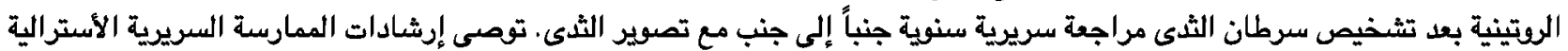

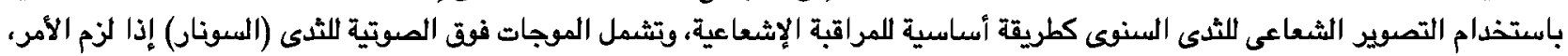

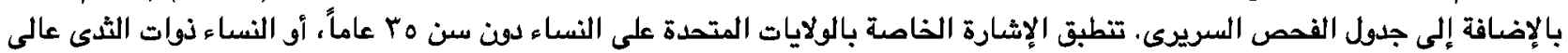

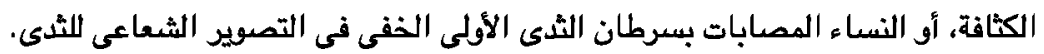

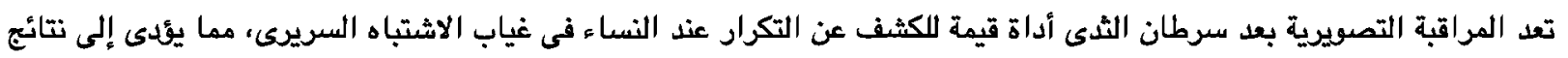

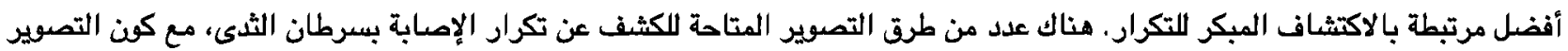

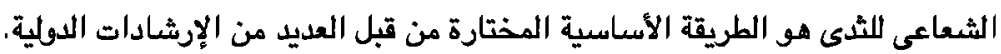

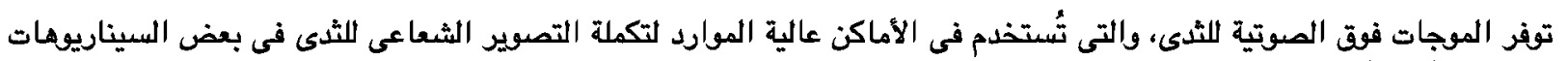

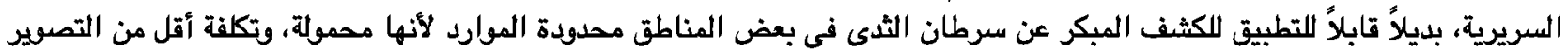

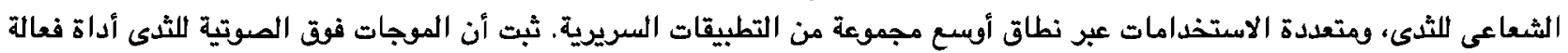

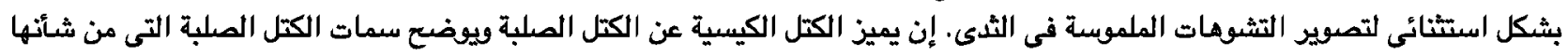

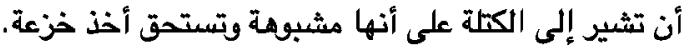

